shows that the development of the human potential of servicemen is not only the result of an increase in the standard of living of servicemen, but also of an increase in the quality of educational and health services, increase of social protection, and progressive (socially significant) changes in the labor and welfare system. The factors that hamper the development of the human potential of military personnel are clarified.

The authors make a conclusion that at present there is a generally accumulated positive experience in the implementation of human development factors for the National Guard servicemen of Russia. It is a partial increase in the standard of living, modernization of the education system and health care and working conditions and significant improvement of the life of military personnel. To solve the basic problems of the development of human potential of servicemen the authors propose: 1) a steady increase in the real monetary allowance of servicemen; 2) systemic modernization of the quality of working life of military personnel; 3) the adoption and implementation of the Federal Law «On the Social Development of Military Units of the National Guard Troops of the Russian Federation".

Keywords: human potential development, National Guard, serviceman, human potential of servicemen

УЗЮМОВА Наталья Владимировна - аспирант департамента социологии, истории и философии Финансового университета при Правительстве РФ (125993, Россия, г. Москва, Ленинградский пр-кт, 49; nataly@uzyumova.ru)

\title{
ПРЕДВАРИТЕЛЬНАЯ АДАПТАЦИЯ НОВЫХ СОТРУДНИКОВ КАК ФАКТОР СОЦИАЛЬНОЙ ЭФФЕКТИВНОСТИ КОРПОРАТИВНОЙ КУЛЬТУРЫ
}

Аннотация. Статья посвящена проблеме влияния корпоративной культуры организации на социальную эффективность адаптации новых сотрудников. Особое значение в данном процессе играет предварительная адаптация. Автор рассматривает теоретические аспекты данной проблематики, формулирует собственное определение социальной эффективности управления адаптацией новых сотрудников и предлагает критерии ее оценки. Статья также содержит результаты эмпирического исследования, проведенного автором.

Ключевые слова: адаптация новых сотрудников, корпоративная культура, социальная эффективность управления корпоративной культурой

$\Pi$ овышение конкурентоспособности российской экономики и социальноинновационного потенциала общества в целом возможно только в условиях высокой социальной эффективности на каждом из уровней организации общества. Между тем еще не сформирована устойчивая, принимаемая большинством методика оценки эффективности управленческой деятельности, в т.ч. при адаптации сотрудника на новом рабочем месте. Данная ситуация характерна даже для крупных международных компаний, текучка кадров в которых оборачивается значительными потерями. Одним из возможных решений является развитие такой корпоративной культуры организации, которая способствовала бы наиболее эффективной социальной адаптации сотрудников. Рассмотрим такие аспекты более подробно.

Корпоративную культуру компании можно охарактеризовать как «комплекс разделяемых всеми поведенческих норм, артефактов, ценностей, представлений и понятий, которые организация создает по мере того, как она учится преодолевать препятствия внутреннего и внешнего характера на пути к процветанию» [Oden 1997: 32].

Наибольший интерес к культуре как методу непрямого управления существует в компаниях, работающих в сфере интеллектуальных услуг, где изменчи- 
вая высококонкурентная внешняя среда вкупе с высокой квалификацией персонала снижают эффективность традиционных методов управления. Однако если сотрудники обладают единым представлением о корпоративных ценностях и нормах поведения, то нет необходимости давать указания в каждой конкретной ситуации - работники самостоятельно примут правильное решение, руководствуясь внутренними ориентирами. Таким образом, культура организации помогает управлять бизнес-процессами без развитых бюрократических структур.

Управленческая деятельность тесно связана с вопросом ее эффективности. Последняя, будучи оценочной категорией, указывает на соотношение между затраченными ресурсами и полученным результатом (в рамках достижения определенной цели). При этом, если речь идет об общественно-экономической деятельности, полученный эффект, помимо собственно экономического среза, имеет также и социальное выражение.

В целях нашего исследования критерий эффективности понимается как «решающее правило, на основании которого делается вывод о достигнутом показателе эффективности» [Тюриков, Якунин 2011: 113].

Поскольку для поддержания и воспроизводства сформировавшейся корпоративной культуры, помимо деятельности высшего руководства, решающее значение имеют отбор персонала и обеспечение последующей производственной адаптации, то одним из критериев социальной эффективности управления корпоративной культурой выступает адаптация новых работников предприятия.

Адаптация в производственной организации - это процесс включения индивида в трудовую деятельность и освоения им условий, практик трудовых отношений, норм и правил, принятых в данной организации ${ }^{1}$. Главной задачей производственной адаптации выступает освоение относительно стабильных условий организации, решение повторяющихся, типичных проблем путем использования принятых способов социального поведения.

Соответственно, наше рабочее определение принимает следующий вид: социальная эффективность управления адаптацией новых сотрудников есть соответствие социальных результатов деятельности руководства по обеспечению условий адаптации, с одной стороны, и позитивная оценка сотрудниками такой управленческой деятельности - с другой.

Социальные результаты управления адаптацией новых сотрудников, в свою очередь, должны отвечать следующим характеристикам:

- служить целям развития организации;

- способствовать активизации человеческого капитала;

- соответствовать ожиданиям как вновь принятых, так и уже осуществляющих трудовую деятельность сотрудников;

- быть воспроизводимыми, приводить к устойчивому результату.

Система отбора персонала призвана идентифицировать и набирать людей, обладающих определенными знаниями, навыками и способностями, позволяющими им успешно выполнять работу. Однако при окончательном отборе предпочтение отдается тем кандидатам, которые в большей степени совместимы с корпоративной культурой организации [Юшкова, Красниковский 2018: 112].

Важно отметить, что новый сотрудник получает представление об организации и об ее корпоративной культуре задолго до вступления в должность. Уже на этапе предварительной адаптации - во время выбора компании, при прохождении собеседования и предварительных испытаний - соискатель и организа-

1 Социология труда. Теоретико-прикладной толковый словарь (отв. ред. В.А. Ядов). СПб: Наука. 2006. C. 195. 
ция озвучивают взаимные ожидания, требования и преимущества в сравнении с другими участниками рынка труда.

Следовательно, социальная эффективность адаптации нового сотрудника во многом зависит от того, насколько достоверно соискатель информирован не только о непосредственном содержании работы, которую ему необходимо выполнять, но и об особенностях корпоративной культуры данной конкретной организации.

Таким образом, целью нашего исследования является изучение влияния корпоративной культуры коммерческих организаций на социальную эффективность адаптации новых сотрудников. Объектом исследования выступает социальная адаптация новых членов организации, т.е. работников, чей трудовой страж в данной компании не превышает одного года. Предметом данного исследования является влияние корпоративной культуры организации на эффективность адаптации новых работников.

Цели данного исследования достаточно полно отвечают критерии анализа корпоративной культуры, предложенные С.П. Роббинсом: это 1) личная инициатива и степень риска; 2) направленность действий; 3) идентичность; 4) управленческая поддержка и контроль; 5) согласованность действий и модели взаимодействия; 6) система вознаграждений; 7) способ разрешения конфликтов.

Данная модель была расширена введением дополнительного критерия, который описывает кадровую политику организации.

Для анализа были выбраны материалы трех международных компаний, имеющих свои филиалы в России: Mediascop, PricewaterhouseCoopers $(P w C)$ и Ernst $\&$ Young $(E Y)$. Данные организации осуществляют экспертизу в сфере финансового аудита, маркетинга и консалтинговых услуг и занимают лидирующие позиции на рынке.

Наибольший интерес в данном контексте представляют публикации, направленные на привлечение потенциальных сотрудников, а именно корпоративные сайты ${ }^{1}$ (в т.ч. разделы «Карьера», «О нас»), страницы на интернет-порталах по подбору персонала $(h h . r u)$. При этом ввиду разнородности информации из анализа были исключены видео- и фотоизображения. Важно отметить, что публикации на корпоративных ресурсах во многом являются официальным взглядом на корпоративную культуру и в дальнейшем будут проверены на соответствие реальности уже в процессе осуществления сотрудником трудовой деятельности.

Анализ материалов всех представленных компаний позволяет говорить о высокой нацеленности на результат, поскольку ключевыми категориями (лидерами по частоте упоминания) является триада «проект» - «задача» - «решение».

Также высока ценность понятий «развитие» и «движение вперед», которые связаны с «прокачкой» (Mediascop) профессиональных навыков и личностных качеств. Красной нитью проходит взаимосвязь целей развития организации и сотрудника.

С направленностью действий тесно связаны личная инициатива и степень риска, которые допустимы в корпоративной культуре той или иной организации.

Например, в Mediascop поощряется самостоятельность и умение бросить вызов: «самим ставить себе задачи», «то, чем мы занимаемся, не делает больше никто». В таких условиях важен экспертный контроль, который исходит не

\footnotetext{
1 РwС в России. Доступ: https://www.pwc.ru/ru.html (проверено 27.12.2018); ЕY - Россия. Доступ: https://www.ey.com/ru/ru/home (проверено 27.12.2018), Mediascop в России. Доступ: http://mediascope. net/ (проверено 27.12.2018).
} 
столько от руководителя, сколько от коллег - таких же профессионалов, которые могут квалифицированно оценить конкретное решение.

Для $E Y$ характерен командный подход, благодаря которому «никто не оказывается один на один с проблемной ситуацией», при этом каждый сотрудник стремится обеспечить «высочайшее качество оказываемых услуг».

Рассмотрим такой критерий, как идентичность - мера отождествления сотрудника с организацией.

Поскольку каждый отдельно взятый сотрудник хочет получать от работы не только материальное вознаграждение, но и моральное удовлетворение от своей роли в коллективе, то задача компании - создать такие условия и организацию труда, которые позволят сотруднику гордиться своей принадлежностью к данной организации, членством в ней.

Характерно, что тексты всех трех компаний написаны с позиции «мы». Тем не менее в материалах Mediascope присутствует и личная позиция («я выбрал», «я работал», «мой рабочий день»). На сайте $P w C$ акцент сделан на сетевую структуру и масштаб корпорации: «нас более 250000 сотрудников PwC в мире», «мы работаем в 158 странах».

Об уровне идентификации с компанией свидетельствует и внешний вид сотрудников: так, $E Y$ и $P w C$ требуют соблюдения дресс-кода, в т.ч. при прохождении собеседования, т.к. каждый сотрудник является «лицом компании» и действует от ее имени. Для корпоративной культуры Mediascop характерен менее формальный подход.

Следующий критерий анализа корпоративной культуры - особенности кадровой политики организации. Работники крупных организаций, как правило, имеют достаточно высокие шансы на внутрифирменное продвижение по карьерной лестнице, что обусловлено разветвленной иерархической структурой [Персикова 2015: 103].

Прозрачность основных правил и параметров, на основании которых происходит перемещение между карьерными позициями, способствует повышению уровня мотивации сотрудников, поощряет их следовать определенным правилам игры. Так, коллега, получивший продвижение или зачисленный в кадровый резерв, становится ролевой моделью для других сотрудников, побуждая следовать его примеру.

В материалах $P w C$ и $E Y$ присутствует наглядное описание карьерных позиций и примерные сроки нахождения в той или иной должности.

Mediascope также заявляет о возможностях карьерного роста, но в менее структурированном виде, не давая целостной картины: «есть вертикальный рост старший и ведущий специалист», «хороший ассистент за год-полтора вырастает до младшего менеджера».

Модели внутрифирменного взаимодействия дают представление о силе и направлении связей между отделами. От того, насколько хорошо налажены отношения между структурными единицами, зависит обмен информацией, идеями, опытом успешного решения тех или иных задач.

В материалах Mediascope описывается успешное взаимодействие: «на регулярных митапах команды рассказывают о своих проектах», «у нас часто бывают встречи внутри отдела или по решению конкретной задачи».

Корпоративная культура $E Y$ также ориентирована на работу в команде и создание проектных групп под конкретные задачи. Также ее сотрудники должны быть готовы к командировкам, в т.ч. в самые отдаленные регионы.

Следующий критерий - «управленческая поддержка» - помогает оценить корпоративную культуру с точки зрения проницаемости административных 
барьеров, уровня доверия между подчиненными и руководителями, дистанции между сотрудниками разного уровня.

Организации с сильной корпоративной культурой основываются на принципе «производительность через людей», что подразумевает единый сплоченный коллектив без демонстративного разделения на управляющих и подчиненных.

Так, корпоративная этика большинства международных компаний, в т.ч. работающих в России, предписывает сотрудниками обращение друг к другу и к руководству на «ты», используя форму имени без отчества. Таким образом подчеркивается демократичность управления, общение на равных, готовность руководителя уделять внимание нуждам сотрудников [Вопросы культуры... 2012: 314].

Для корпоративной культуры Mediascop характерны следующие черты: групповое принятие решений, открытость руководителя для новых идей и общения с подчиненными; «нет строгого подчинения», «доверие со стороны руководства - у них всегда открыты двери для любого разговора и идеи», при этом «руководители строгие, но справедливые».

В $P w C$ руководитель - в первую очередь лидер («лидерство - умение вдохновлять других становиться лучше»), тот, кто достойно проявил себя, постоянно осваивает новые роли и задачи, «стал первым среди равных».

Такие критерии, как способ разрешения конфликтов и вознаграждение, фактически не представлены в корпоративных материалах, знакомство с ними, вероятно, происходит во время собеседования и при прохождении испытательного срока непосредственно в компании.

Подводя итоги, можно сделать вывод, что все изученные компании имеют сильные корпоративные культуры, которые оказывают значительное управленческое воздействие на своих сотрудников.

Также данные корпоративные культуры характеризуются большой нацеленностью на результат, предполагают командную организацию работы, возможность горизонтального и вертикального карьерного роста внутри организации, доверие и поддержку со стороны руководителей, которые сочетаются с контролем срока и качества выполняемой работы. Все три компании ориентированы на набор инициативных, самостоятельных сотрудников, которые готовы решать новые задачи и брать на себя ответственность за полученные результаты.

При этом $P w C$ и $E Y$ представляют сотрудникам налаженную, четко выстроенную траекторию карьерного продвижения, следование которой требует прохождения корпоративного обучения, довольно жесткого контроля со стороны коллег и наставников. Корпоративная культура Mediascop более гибкая и предполагает больший уровень свободы, в т.ч. при выборе графика работы и соблюдении дресс-кода.

Таким образом, представленные в открытом доступе материалы дают соискателям довольно полное представление о корпоративных культурах организаций, что является первым шагом к успешной предварительной адаптации новых сотрудников и их успешного включения в трудовую деятельность.

\section{Список литературы}

Вопросы культуры речи (отв. ред. А. Шмелев). 2012. М.: Языки славянских культур. 384 с.

Персикова Т.Н. 2015. Корпоративная культура. М.: Логос. 288 с.

Тюриков А.Г., Якунин А.С. 2011. Оценка социальной эффективности управления регионом по критерию качества жизни населения. - Вестник Военного университета. № 1(25). С. 111-117. 
Юшкова С.А., Красниковский В.Я. 2018. Культурная предрасположенность и успешность профессиональной адаптации выпускников вузов. - Власть. Т. 26. № 8. C. 111-117.

Oden H.W. 1997. Managing Corporate Culture, Innovation and Entrepreneurship. Westport, Conn.: Quorum Books. 279 p.

UZYUMOVA Natal'ya Vladimirovna, postgraduate student of the Department of Sociology, History and Philosophy, Financial University under the Government of the Russian Federation (49 Leningradsky Ave, Moscow, Russia, 125993; nataly@uzyumova.ru)

\title{
PRELIMINARY ADAPTATION OF NEW EMPLOYEES AS A FACTOR OF SOCIAL EFFICIENCY OF CORPORATE CULTURE
}

\begin{abstract}
The article is devoted to the problem of the influence of corporate culture of the organization on the social efficiency of adaptation of new employees, and pre-adaptation is of particular importance in this process. The author examines the theoretical aspects of this problem, formulates her own definition of the social efficiency of management adaptation of new employees and offers criteria for its evaluation. The article also contains the results of empirical research conducted by the author.

Keywords: adaptation of new employees, corporate culture, social efficiency of corporate culture management
\end{abstract}

